Efficient Vol 1(1) (2018): 1-7 DOI: https://doi.org/10.15294/efficient.vii.27214
Indonesian Journal of Development Economics
http: https://journal.unnes.ac.id/sju/index.php/efficient

\title{
Analisis Penyerapan Dana Bagi Hasil Cukai Tembakau Tahun Anggaran 2015 di Kabupaten Kudus
}

\author{
Willy Irmawan ${ }^{凶}$ \\ Jurusan Ekonomi Pembangunan, Fakultas Ekonomi, Universitas Negeri Semarang \\ Permalink/DOI: https://doi.org/10.15294/efficient.vii1.27214 \\ Received: July 2017; Accepted: October 2017; Published: January 2018
}

\begin{abstract}
Collecting data using interviews, and documentation. The result of this research is the Kudus Regency authority arranged in Bupati Regulation Kudus No. 32 Year 2013 on Guidelines for Management of Revenue Sharing Tobacco Excise in Kudus District. The main constraint is the Minister of Finance Regulation No. 20 / PMK.07 / 2009 and No. 84 / PMK.07 / 2008 on the use of Revenue Sharing Tobacco Excise and Sanctions Over Allocation Abuse Revenue Sharing Tobacco Excise. Spesials constraints faced in the implementation of different programs in each government department. Efforts is through coordination meetings with the users in order to maximize their absorption DBHCHT and Kudus Regent also sent a letter to the Finance Minister and the President to propose a review of the regulations by expanding the range of activities.
\end{abstract}

Keywords: Absorption DBHCHT, Regional Autonomy, Kudus Regency

\begin{abstract}
Abstrak
Pengumpulan data menggunakan metode wawancara, dan dokumentasi. Hasil penelitian ini adalah kewenangan Kabupaten Kudus diatur dalam Peraturan Bupati Kudus No. 32 Tahun 2013 tentang Pedoman Pengelolaan Dana Bagi Hasil Cukai Hasil Tembakau di Kabupaten Kudus. Kendala dalam penyerapan DBHCHT terbagi menjadi kendala utama dan kendala khusus. Kendala utamanya adalah Peraturan Menteri Keuangan No. 20/PMK.07/2009 dan Nomor 84/PMK.07/2008 tentang Penggunaan Dana Bagi Hasil Cukai Hasil Tembakau dan Sanksi Atas Penyalahgunaan Alokasi Dana Bagi Hasil Cukai Hasil Tembakau. Kendala khusus yang dihadapi dalam pelaksanaan program berbeda-beda di setiap SKPD. Upaya yang dilakukan adalah melalui rapat koordinasi dengan pengguna DBHCHT agar memaksimalkan penyerapannya dan Bupati Kudus juga mengirim surat kepada Menteri Keuangan dan Presiden RI untuk mengusulkan peninjauan peraturan dengan memperluas cakupan jenis kegiatan.
\end{abstract}

Kata Kunci: Absorption DBHCHT, Regional Autonomy, Kudus Regency

How to Cite: Irmawan, W. (2018). Analisis Penyerapan Dana Bagi Hasil Cukai Tembakau Tahun Anggaran 2015 di Kabupaten Kudus. EFFICIENT Indonesian Journal of Development Economics, 1(1), 1-7. https://doi.org/10.15294/efficient.vii1.27214

(c) 2018 Universitas Negeri Semarang. All rights reserved

\footnotetext{
Alamat Korespondensi :

Gedung L2 Lantai 2 FE Unnes

Kampus Sekaran, Gunungpati, Semarang, 50229

Email : jurnalefficient@gmail.com
} 


\section{PENDAHULUAN}

Otonomi daerah memiliki pengertian sebagaimana tertera di dalam Undang-Undang Nomor 23 Tahun 2014 tentang Pemerintahan Daerah adalah hak, wewenang, dan kewajiban daerah otonom untuk mengatur dan mengurus sendiri Urusan Pemerintahan dan kepentingan masyarakat setempat dalam sistem Negara Kesatuan Republik Indonesia (NKRI). Sesuai uraian tersebut, pemerintah daerah diberi kewenangan dalam mengatur daerahnya sendiri sesuai kebutuhan dan karakteristik daerahnya, termasuk dalam mengatur anggaran belanja daerah dan menetapkan strategi untuk meningkatkan pendapatan asli daerahnya sendiri. Menurut Syafrudin (1991:23), otonomi mempunyai makna kebebasan dan kemandirian tetapi bukan kemerdekaan. Kebebasan terbatas atau kemandirian itu adalah wujud pemberian kesempatan yang harus dipertanggungjawabkan.

Tujuan otonomi daerah pada dasarnya diarahkan untuk memacu pemerataan pembangunan dan hasil-hasilnya, meningkatkan kesejahteraan rakyat, menggalakkan prakarsa dan peran serta masyarakat, serta meningkatkan pendayagunaan potensi daerah secara nyata, optimal, terpadu, dan dinamis, serta bertanggung jawab sehingga memperkuat persatuan dan kesatuan bangsa, mengurangi beban pemerintah pusat dan campur tangan terhadap daerah dan memberikan peluang untuk koordinasi tingkat lokal atau daerah (Suseno,2013).

Pendapatan daerah adalah pendapatan yang diperoleh daerah yang dipungut berdasarkan peraturan daerah sesuai dengan peraturan perundang-undangan. Pendapatan Asli Daerah (PAD) bersumber dari Pajak Daerah, Retribusi Daerah dan hasil pengelolaan kekayaan daerah.
Dana Bagi Hasil (DBH) merupakan salah satu pendapatan daerah selain Dana Alokasi Umum (DAU) dan Dana Alokasi Khusus (DAK) yang bersumber dari APBN. DBH dialokasikan kepada daerah penghasil berdasarkan angka persentase tertentu dengan tujuan mengurangi ketimpangan kemampuan keuangan antara Pemerintah Pusat dan Daerah.

Kabupaten Kudus adalah penerima Dana Bagi Hasil Cukai Hasil Tembakau (DBHCHT) terbesar di Jawa Tengah diantara Kabupaten lainnya, hal ini dikarenakan Kabupaten Kudus adalah daerah penghasil cukai tembakau yang besar dan potensial di Jawa Tengah. Dana Bagi Hasil Cukai Hasil Tembakau yang selanjutnya disingkat DBHCHT adalah penerimaan negara dari cukai hasil tembakau yang dibuat di Indonesia dibagikan kepada provinsi penghasil cukai hasil tembakau sebesar $2 \%$ (dua persen).

Pembagian DBHCHT dilanjutkan lagi dari provinsi ke kabupaten/kota, dengan komposisi $30 \%$ untuk provinsi penghasil, $40 \%$ untuk kabupaten/kota daerah penghasil, dan 30\% untuk kabupaten/kota lainnya yang ada di wilayah provinsi yang bersangkutan. Berikut ini adalah tabel perolehan DBHCHT tahun 2015 seprovinsi Jawa Tengah.

Pada Tabel 1 Kabupaten Kudus merupakan daerah yang paling banyak mendapat DBHCHT dibandingkan dengan kabupaten atau kota di Provinsi Jawa Tengah lainnya. Besarnya angka DBHCHT yang diterima pada tahun 2015 ternyata penyerapannya hanya mencapai $17,8 \%$. Hal ini disebabkan adanya Peraturan Menteri Keuangan Nomor 20/PMK.07/2009 dan Nomor 84/PMK.07/2008 tentang Penggunaan Dana Bagi Hasil Cukai Hasil Tembakau dan Sanksi Atas Penyalahgunaan Alokasi Dana Bagi Hasil 
Tabel 1. Dana Bagi Hasil Cukai Hasil Tembakau Kabupaten / Kota di Jawa Tengah Tahun Anggaran 2015 (dalam Ribuan Rupiah)

\begin{tabular}{|c|c|}
\hline PENERIMA & JUMLAH (Rp) \\
\hline Provinsi Jawa Tengah & 188.468 .339 \\
\hline Kabupaten Banjarnegara & 6.103 .153 \\
\hline Kabupaten Banyumas & 5.677 .222 \\
\hline Kabupaten Batang & 5.747 .793 \\
\hline Kabupaten Blora & 8.404 .711 \\
\hline Kabupaten Boyolali & 13.583 .144 \\
\hline Kabupaten Brebes & 5.735 .397 \\
\hline Kabupaten Cilacap & 5.711 .378 \\
\hline Kabupaten Demak & 13.817 .684 \\
\hline Kabupaten Grobogan & 9.781 .136 \\
\hline Kabupaten Jepara & 5.975 .693 \\
\hline Kabupaten Karanganyar & 6.904 .034 \\
\hline Kabupaten Kebumen & 7.424 .972 \\
\hline Kabupaten Kendal & 26.587 .283 \\
\hline Kabupaten Klaten & 15.168 .602 \\
\hline Kabupaten Kudus & 136.410 .313 \\
\hline Kabupaten Magelang & 12.469 .873 \\
\hline Kabupaten Pati & 5.730 .858 \\
\hline Kabupaten Pekalongan & 5.644 .881 \\
\hline Kabupaten Pemalang & 6.215 .510 \\
\hline Kabupaten Purbalingga & 6.401 .876 \\
\hline Kabupaten Purworejo & 6.534 .426 \\
\hline Kabupaten Rembang & 8.932 .740 \\
\hline Kabupaten Semarang & 8.462 .257 \\
\hline Kabupaten Sragen & 6.995 .433 \\
\hline Kabupaten Sukoharjo & 6.944 .842 \\
\hline Kabupaten Tegal & 6.378 .479 \\
\hline Kabupaten Temanggung & 27.642 .198 \\
\hline Kabupaten Wonogiri & 6.524 .070 \\
\hline KabupatenWonosobo & 10.765 .676 \\
\hline Kota Magelang & 5.688 .905 \\
\hline Kota Pekalongan & 7.205 .229 \\
\hline Kota Salatiga & 7.928 .600 \\
\hline Kota Semarang & 7.281 .907 \\
\hline Kota Surakarta & 7.352 .414 \\
\hline Kota Tegal & 5.626 .769 \\
\hline JUMLAH & 628.227.797 \\
\hline
\end{tabular}

Sumber : Peraturan Gubernur Jawa Tengah No.27 Tahun 2015 tentang Perubahan Perkiraan Alokasi DBHCHT Bagian Pemerintah Provinsi Jawa Tengah dan Pemerintah Kabupaten / Kota di Jawa Tengah Tahun Anggaran 2015
Pelaksanaan otonomi daerah di Kabupaten Kudus saat ini belum berjalan semestinya terkait penggunaan DBHCHT dikarenakan terkendala oleh aturan Pemerintah Pusat dalam hal ini adalah Kementerian Keuangan yang membatasi penggunaan DBHCHT hanya untuk lima kelompok kegiatan saja. Hal ini tidak sejalan dengan pelaksanaan Cukai Hasil Tembakau, yang membatasi ruang gerak penggunaan anggaran DBHCHT sehingga tidak dapat digunakan secara optimal. Berdasarkan Peraturan Menteri Keuangan Nomor 20/PMK.07/2009 dan Nomor 84/PMK.07/2008 alokasinya hanya digunakan untuk mendanai kelompok kegiatan sebagai berikut:

1. Peningkatan Kualitas Bahan Baku

2. Pembinaan Industri Hasil Tembakau

3. Pembinaan Lingkungan Sosial

4. Sosialisasi Ketentuan di Bidang Cukai

5. Pemberantasan Barang Kena Cukai Ilegal. otonomi daerah yang seharusnya memberi kewenangan kepada Daerah untuk dapat mengatur daerahnya sendiri, termasuk juga dalam pengelolaan sumber-sumber pendapatan daerah. Penelitian ini juga berkaitan dengan konsep desentralisasi fiskal. Secara teoritis, desentralisasi fiskal menggeser pengelolaan sumber daya keuangan dan pengambilan keputusan dari tingkat nasional ke tingkat pemerintah daerah (Michael Tonhodzai et al:2015).

\section{METODE PENELITIAN}

Penelitian ini adalah deskriptif kualitatif, yaitu pendekatan dimana penelitian yang akan memberi gambaran secara cermat mengenai 
individu atau kelompok tertentu tentang keadaan dan gejala yang terjadi dengan meggunakan penjelasan deskripsi kalimat agar dapat dipahami secara mendalam dan menyeluruh. Fokus penelitian ini adalah : kewenangan Pemerintah Kabupaten Kudus dalam pengelolaan dan penggunaan DBHCHT tahun anggaran 2015 berkaitan dengan implementasi otonomi daerah, faktor-faktor apa saja yang menjadi kendala dalam pengelolaan dan penggunaan DBHCHT tahun anggaran 2015, dan upaya pemerintah Kabupaten Kudus dalam pengelolaan dan penggunaan DBHCHT tahun anggaran 2015. Lokasi penelitian ini adalah di Asisten Ekonomi, Pembangunan dan Kesejahteraan Rakyat Sekretaris Daerah Kabupaten Kudus, Dinas Pendapatan dan Pengelolaan Keuangan Daerah Kabupaten Kudus, Dinas Cipta Karya dan Tata Ruang Kabupaten Kudus, Kantor

Lingkungan Hidup, dan Dinas Pertanian, Perikanan dan Kehutanan Kabupaten Kudus. Sumber data yang digunakan dalam penelitian ini adalah data primer dan data sekuder. Metode pengumpulan data yang dipergunakan dalam penelitian adalah: observasi, wawancara, studi kepustakaan, penelusuran data online, dan dokumentasi Teknik analisis yang digunakan adalah kualitatif, yaitu dengan menguraikan dan menjelaskan hasil-hasil penelitian dalam bentuk kata-kata lisan maupun tertulis. Analisis data dilakukan dengan mengorganisasikan data, menjabarkannya ke dalam unit-unit, melakukan sintesa, menyusun ke dalam pola, memilih mana yang penting dan yang akan dipelajari, dan membuat kesimpulan yang dapat diceritakan kepada orang lain.

\section{HASIL DAN PEMBAHASAN}

Penelitian ini bertujuan untuk mengetahui bagaimana kewenangan Pemerintah Kabupaten Kudus dalam pengelolaan dan penggunaan DBHCHT berkaitan dengan pelaksanaan otonomi daerah, kendala dalam penyerapan DBHCHT dan upaya yang dilakukan dalam penggunaan dan pengelolaan DBHCHT tahun anggaran 2015.

DBHCHT direalisasikan pertama kali pada tahun 2008 dalam Undang-Undang No.45 tahun 2007 tentang APBN tahun anggaran 2008, kemudian ditindaklanjuti dengan terbitnya Permenkeu No.6o/PMKo7/2008 yang menetapkan alokasi DBHCHT tahun anggaran 2008 . Tabel 4.2 adalah DBHCHT yang diterima Kabupaten Kudus dari tahun 2008 - 2016.

Tabel 2. DBHCHT yang Diterima Kabupaten Kudus Tahun 2008-2016

\begin{tabular}{ccc}
\hline No. & $\begin{array}{c}\text { Tahun } \\
\text { Anggaran }\end{array}$ & $\begin{array}{c}\text { Jumlah } \\
\text { (Rupiah) }\end{array}$ \\
\hline 1 & 2008 & 17.207 .191 .978 \\
2 & 2009 & 82.409 .330 .847 \\
3 & 2010 & 53.262 .539 .633 \\
4 & 2011 & 60.824 .479 .283 \\
5 & 2012 & 52.579 .441 .278 \\
6 & 2013 & 108.037 .276 .454 \\
7 & 2014 & 104.514 .311 .801 \\
8 & 2015 & 136.410 .313 .000 \\
9 & 2016 & 140.751 .030 .000 \\
\hline
\end{tabular}

Sumber : Bidang Perekonomian Sekretaris Daerah Kabupaten Kudus 
Pada tahun 2015 Kabupaten Kudus mendapatkan alokaasi DBHCHT sebesar 136,4 Miliar Rupiah. Angka DBHCHT yang diterima Kabupaten Kudus tahun 2015 bergantung pada nilai pita cukai yang disetor ke pemerintah pusat tahun 2014 yang diakumulasikan dengan daerah penghasil cukai lain seluruh Provinsi Jawa Tengah. Pada tahun anggaran 2015 jumlah DBHCHT Kabupaten Kudus mengalami perubahan dari 136,41 Miliar Rupiah menjadi 271,58 Miliar Rupiah, jumlah ini berasal dari DBHCHT murni tahun 2015 ditambah dengan total sisa penggunaan DBHCHT tahun-tahun sebelumnya. Perubahan jumlah DBHCHT dikarenakan adanya perubahan dalam penyusunan APBD Kabupaten Kudus, namun alokasi DBHCHT yang masuk dalam APBD-P tahun 2015 hanya sebesar 237,98 Miliar Rupiah, sehingga terdapat selisih jumlah total DBHCHT tahun 2015 dengan APBD-P 2015 sebesar 33,59 Miliar Rupiah yang digunakan untuk penganggaran tahun berikutnya.

Secara garis besar wewenang Daerah dalam pengelolaan dan penggunaan DBHCHT telah diatur dalam Peraturan Menteri Keuangan Nomor 20/PMK.o7/2009 dan Nomor 84/PMK.o7/2008 tentang Penggunaan Dana Bagi Hasil Cukai Hasil Tembakau dan Sanksi Atas Penyalahgunaan Alokasi Dana Bagi Hasil Cukai Hasil Tembakau. Namun, Pemerintah Daerah Kabupaten Kudus menciptakan peraturan daerah demi kelancaran pengelolaan dan penggunaannya tanpa menyalahi dan melanggar aturan perundang-undangan yang berlaku. Dalam Perda tersebut juga tertera secara detail dan jelas tentang bagaimana mekanisme penggunaan dan pengelolaan DBHCHT di Kabupaten Kudus dari mulai tahap penyusunan hingga tahap pelaporan.
Peraturan Bupati Kudus No. 32 Tahun 2013 tentang Pedoman Pengelolaan Dana Bagi Hasil Cukai Hasil Tembakau di Kabupaten Kudus terbit karena didalam Peraturan Menteri Keuangan Nomor 20/PMK.07/2009 dan Nomor 84/PMK.o7/2008 tentang Penggunaan Dana Bagi Hasil Cukai Hasil Tembakau dan Sanksi Atas Penyalahgunaan Alokasi Dana Bagi Hasil Cukai Hasil Tembakau tidak ada aturan yang jelas dalam mekanisme pengelolaan dan penggunaan DBHCHT serta kelompok kegiatan yang tercantum juga masih bersifat umum serta terdapat beberapa point di dalam Peraturan Menteri Keuangan yang tidak sesuai dengan karakteristik Kabupaten Kudus Maka dari itu, Peraturan Bupati Kudus No. 32 Tahun 2013 tentang Pedoman Pengelolaan Dana Bagi Hasil Cukai Hasil Tembakau di Kabupaten Kudus ini terbit adalah sebagai pedoman penggunaan DBHCHT yang sesuai dengan kebutuhan, prioritas dan karakteristik Kabupaten Kudus. Dalam Peraturan Bupati Kudus No. 32 Tahun 2013 tentang Pedoman Pengelolaan Dana Bagi Hasil Cukai Hasil Tembakau di Kabupaten Kudus menjelaskan bagaimana tata cara pengelolaan dan penggunaan DBHCHT di Kabupaten Kudus.

Kendala dan masalah yang dihadapi Kabupaten Kudus dalam penyerapan DBHCHT dibagi menjadi dua faktor, yaitu faktor kendala umum dan faktor kendala khusus. Faktor kendala khusus adalah kendala yang dihadapi oleh setiap SKPD terkait penggunaan dan pengelolaan DBHCHT. Faktor kendala utama yang dihadapi oleh kelima SKPD dalam penyerapan DBHCHT tahun anggaran 2015 adalah adanya Peraturan Menteri Keuangan Nomor 20/PMK.o7/2009 dan Nomor 84/PMK.o7/2008 tentang Penggunaan Dana Bagi Hasil Cukai Hasil Tembakau dan Sanksi Atas Penyalahgunaan Alokasi Dana Bagi 
Hasil Cukai Hasil Tembakau. Peraturan Menteri tersebut sangat membatasi ruang gerak penggunaan DBHCHT di Kabupaten Kudus, ditambah lagi peraturan tersebut besifat kaku dan tidak mengalami perubahan setiap tahunnya. Akibatnya alokasi DBHCHT tidak bisa mengakomodasi kebutuhan Kabupaten Kudus yang setiap tahunnya mengalami perubahan.

Faktor kendala khusus keempat SKPD pengguna DBHCHT tahun anggaran 2015 berbeda-beda. Kendala yang dihadapi DPPKD Kabupaten Kudus adalah tidak adanya UMKM di lingkungan IHT yang sudah berbadan hukum. Akibatnya, alokasi DBHCHT tahun anggaran tahun 2015 di DPPKD yang berupa program dana bergulir tidak dapat terserap sama sekali. Kendala yang dihadapi Dinas Pertanian, Perikanan dan Kehutanan Kabupaten Kudus adalah penerima bantuan hibah berupa bibit tanaman dan bibit ikan kepada kelompok tani dan kelompok budidaya ikan harus sudah berbadan hukum minimal 3 tahun, padahal di Kabupaten Kudus tidak ada kelompok tani dan kelompok peternak ikan yang berbadan hukum. Kendala yang dihadapi Kantor Lingkungan Hidup Kabupaten Kudus adalah adanya tambahan alokasi DBHCHT dari Pemerintah Daerah pada akhir periode tahun 2015, dana tersebut diterima pada bulan November, sehingga dengan waktu yang terbatas dana sebesar 3 Miliar Rupiah tidak dapat digunakan untuk program kegiatan tambahan. Kendala yang dihadapi Dinas Cipta Karya dan Tata Ruang Kabupaten Kudus adalah tidak adanya infrastruktur pedesaan di lingkungan IHT yang perlu diperbaiki karena kondisinya sudah baik karena perbaikan infrastruktur sudah dilakukan di tahun-tahun sebelumnya. Hal ini dikarenakan adanya aturan yang menyatakan bahwa perbaikan infrastruktur pedesaan yang menggunakan alokasi DBHCHT harus berada di lingkungan IHT dan dengan sistem padat karya oleh warga sekitar. Sehingga, Dinas Cipta Karya dan Tata Ruang Kabupaten Kudus tidak dapat melaksanakan progam kegiatannya.

Pemerintah Kabupaten Kudus telah melakukan upaya dalam pengelolaan dan penggunaan DBHCHT tahun anggaran 2015. Hal ini bertujuan untuk memaksimalkan penyerapan anggaran DBHCHT di setiap SKPD di Kabupaten Kudus. Penyerapan anggaran yang maksimal akan sangat berpengaruh terhadap keberhasilan program-program yang dilaksanakan oleh SKPD pengguna DBHCHT tahun 2015. Upaya pemerintah Kabupaten Kudus dalam pengelolaan dan pengggunaan DBHCHT tahun anggaran 2015 adalah melalui rapat-rapat yang dilakukan oleh Asisten Ekonomi, Pembangunan dan Kesejahteraan Rakyat Sekretaris Daerah Kabupaten Kudus yang berperan sebagai koordinator selalu menghimbau kepada seluruh SKPD pengguna DBHCHT tahun anggaran 2015 agar memaksimalkan penyerapannya untuk program-program kegiatan yang telah dianggarkan. Bupati Kudus juga mengusulkan perlunya peninjauan peraturan perundangundangan yang ada dengan memperluas cakupan jenis kegiatan sesuai prioritas dan karakteristik daerah kepada Menteri Keuangan melalui surat tertanggal 10 Desember 2014. Bupati Kudus juga mengirimkan surat kepada Presiden RI tertanggal 20 Februari 2015 dengan nomor surat 976/o483/o1 tentang Penggunaan Dana Bagi Hasil Cukai Hasil Tembakau karena surat yang dikirim kepada Menteri Keuangan tidak mendapatkan tanggapan. Upaya yang dilakukan Pemerintah Kabupaten Kudus dengan mengirim surat kepada Menteri Keuangan dan Presiden RI agar penggunaan DBHCHT diperlonggar adalah langkah yang tepat karena masalah utama yang dihadapi dalam penyerapan DBHCHT di 
Kabupaten Kudus adalah masalah regulasi. Jika berkaitan dengan masalah regulasi, pemerintah pusatlah yang berwenang dalam merubah aturan tentang pengelolaan dan penggunaan DBHCHT.

\section{SIMPULAN}

Pelaksanaan otonomi daerah di Kabupaten Kudus dalam hal pengelolaan dan penggunaan DBHCHT tahun anggaran 2015 telah berjalan dengan baik dengan terbitnya Peraturan Bupati Kudus No. 32 Tahun 2013 tentang Pedoman Pengelolaan Dana Bagi Hasil Cukai Hasil Tembakau di Kabupaten Kudus. Namun pelaksanaan otonomi daerah di Kabupaten Kudus terasa belum sempurna karena adanya Peraturan Menteri Keuangan Nomor 20/PMK.07/2009 dan Nomor 84/PMK.07/2008 tentang Penggunaan Dana Bagi Hasil Cukai Hasil Tembakau dan Sanksi Atas Penyalahgunaan Alokasi Dana Bagi Hasil Cukai Hasil Tembakau yang membatasi ruang gerak pengelolaan dan penggunaan DBHCHT, sehingga berdampak terhadap rendahnya penyerapan DBHCHT tahun anggaran 2015 di Kabupaten Kudus. Disarankan kepada Pemerintah Pusat diharapkan untuk lebih memberi kewenangan kepada Daerah berkenaan dengan penyelenggaraan Pemerintah Daerah sesuai dengan kebutuhan, prioritas dan karakteristik daerah yang ada di dalam konsep otonomi daerah.

\section{DAFTAR PUSTAKA}

Lampiran Peraturan Gubernur Jawa Tengah No.27 Tahun 2015 Tentang Perubahan Perkiraan Alokasi Dana Bagi Hasil Cukai Hasil Tembakau Bagian Pemerintah Provinsi Jawa Tengah Dan Pemerintah Kabupaten/Kota Di Jawa Tengah Tahun Anggaran 2015.

Tonhodzai, Michael. Nyikadzino, Tawanda and Nhema, Alfred, G. 2015. The Utility of Fiscal Decentralization as a Local Governance Reform Strategy in Zimbabwe.
American International Journal of Social Science. Vol. 4, No. 5; October 2015.

Peraturan Menteri Keuangan Nomor 20/PMK.o7/2009 tentang Penggunaan Dana Bagi Hasil Cukai Hasil Tembakau dan Sanksi Atas Penyalahgunaan Alokasi Dana Bagi Hasil Cukai Hasil Tembakau.

Peraturan Menteri Keuangan Nomor 84/PMK.o7/2008 tentang Penggunaan Dana Bagi Hasil Cukai Hasil Tembakau dan Sanksi Atas Penyalahgunaan Alokasi Dana Bagi Hasil Cukai Hasil Tembakau.

Peraturan Bupati Kudus No. 32 Tahun 2013 tentang Pedoman Pengelolaan Dana Bagi Hasil Cukai Hasil Tembakau di Kabupaten Kudus.

Rosalina, Cahya. Suharsono, Agus dan Kholiq Azhari, Abdul. 2014. Implementasi Kebijakan Penggunaan Dana Bagi Hasil Cukai Hasil Tembakau (DBHCHT) di Kabupaten Jember. Artikel Ilmiah Hasil Penelitian Mahasiswa.

Suseno, Deky Aji (2013). EFEKTIVITAS DAN KEMANDIRIAN KEUANGAN DAERAH PROVINSI JAWA TENGAH PASCA DITERAPKANNYA DESENTRALISASI FISKAL. Economics Development Analysis Journal, 2(2). doi:10.15294/edaj.v2i2.1710

Syafrudin, Ateng. 1991. Titik Berat Otonomi Daerah Pada Daerah Tingkat II Dan Pembangunannya. Jakarta : Rineka Cipta.

Undang-Undang Nomor 23 Tahun 2014 tentang Pemerintah Daerah. 